DOE/ET/14052-1

(DE81022404)

$$
\begin{aligned}
& \text { BiNS-95 } \\
& \text { NIIS-25 } \\
& \text { SP-5 }
\end{aligned}
$$

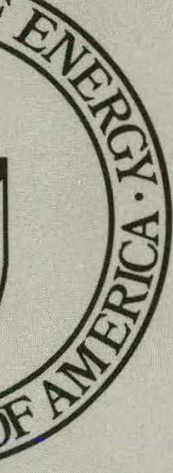

BUILT IN TEST EQUIPMENT (BITE) TO IMPROVE FRONT END LOADER PRODUCTIVITY

Technical Progress Report

Contractor-McDonnell Douglas Electronics Company

May 1981

Contract No. U.S.D.O.E. AC22-80ET14052

\title{
$\rightarrow$ andre
}

U. S. Department of Energy

Assistant Secretary for Fossil Energy Office of Coal Mining 


\section{DISCLAIMER}

This report was prepared as an account of work sponsored by an agency of the United States Government. Neither the United States Government nor any agency Thereof, nor any of their employees, makes any warranty, express or implied, or assumes any legal liability or responsibility for the accuracy, completeness, or usefulness of any information, apparatus, product, or process disclosed, or represents that its use would not infringe privately owned rights. Reference herein to any specific commercial product, process, or service by trade name, trademark, manufacturer, or otherwise does not necessarily constitute or imply its endorsement, recommendation, or favoring by the United States Government or any agency thereof. The views and opinions of authors expressed herein do not necessarily state or reflect those of the United States Government or any agency thereof. 


\section{DISCLAIMER}

Portions of this document may be illegible in electronic image products. Images are produced from the best available original document. 


\title{
DISCLAIMER
}

\begin{abstract}
"This report was prepared as an account of work sponsored by an agency of the United States Government. Neither the United States Government nor any agency thereof, nor any of their employees, makes any warranty, express or implied, or assumes any legal liability or responsibility for the accuracy, completeness, or usefulness of any information, apparatus, product, or process disclosed, or represents that its use would not infringe privately owned rights. Reference herein to any specific commercial product, process, or service by trade name, trademark, manufacturer, or otherwisc, docs nôt neccessarily cunstilule un inply its endorsement, recommendation, or favoring by the United States Government or any agency thereof. The views and opinions of authors expressed herein do not necessarily state or reflect those of the United States Government or any agency thereof,"
\end{abstract}

This report has been reproduced directly from the best available copy.

Available from the National Technical Information Service, U. S. Department of Commerce, Springfield, Virginia 22161.

Price: Printed Copy A04

Microfiche A01

Codes are used for pricing all publications. The code is determined by the number of pages in the publication. Information pertaining to the pricing codes can be found in the current issues of the following publications, which are generally available in most libraries: Energy Research Abstracts, (ERA); Government Reports Announcements and Index (GRA and I); Scientific and Technical Abstract Reports (STAR); and publication, NTIS-PR-360 available from (NTIS) at the above address. 
DOE/ET/14052-1

(DE81022404)

Distribution Category UC-88

\section{BUILT IN TEST EQUIPMENT (BITE) \\ TO IMPROVE FRONT END \\ LOADER PRODUCTIVITY}

TECHNICAL PROGRESS REPORT

MCDONNELL DOUGLAS ELECTRONICS COMPANY

May 1981

U.S. DOE DE-AC01-80ET14052

\section{U.S. Department of Energy}

$\therefore \quad$ Assistant Secretary for Fossil Energy Office of Coal Mining 


\section{ABSTRACT}

This Topical Report describes an equipment system being developed to improve the availability and productivity of large front end loaders used in surface mining operations. The equipment is mounted on the front end loader and includes an operator display and keypad, a microcomputer, machine sensors and a signal conditioner. Safety and machine performance problems are displayed to the operator and a report is printed for the maintenance shop. The BITE equipment, environment and system operation are described. 


\section{TABLE OF CONTENTS}

Section

Title

Page

1.0

EXECUTIVE SUMMARY

5

2.0

BITE HARDWARE .................. 8

2.1

Design Considerations

8

2.1 .1

Environment

Temperature .................. 9

Vibration ....................... 11

Electromagnetic Interference ............ 13

2.1 .2 Maintenance ................. 15

2.2 BITE Components ................ 17

2.2.1 Keypad .................... 17

2.2.2 Display ..................... 19

2.2.3 Microcomputer ..................... 19

2.2.4 Signal Conditioner . . . . . . . . . . . . 25

2.2.5 Machine Parameters ............... 29

Electrical System ................ 29

Engine . . . . . . . . . . . . . . . 33

Torque Converter ................. . . 34

Air System .................. 34

Brake System ................. 35

Hydraulic Systems . . . . . . . . . . . . 36

Lubrication .................. 39

Nitrogen System ................. 39 


\section{TABLE OF CONTENTS (Continued)}

Section

Title

Page

2.2 .6

Operation Parameters

Wheel spin ............... 40

Stability Indicator ........... 41

Speed Stability................ 42

Roll Over Stability ............. 43

Bucket Forces . . . . . . . . . . . . . . 44

Hourmeter ................ 45

2.7 Maintenance Report Printer ........... 44 46

3.0 BITE OPERATION ................... 47

3.1 Power-Up Self Test ............ 47

3.2 Operator Display .................. 48

Alerts ................ 48

Meter Mode Displays ............. . . 55

Maintenance Displays ........... . 57

3.3 Maintenance Reports ... . . . . . . . 59

3.4 Personality Module ............ . 66

4.0 DEVELOPMENT TOOLS ................. 69

$4.1 \quad$ Keypad Monitor .............. 69

4.2 Programmable Histogram ............ 69

4.3 Programmable Meter Mode ........... 70

$5.0 \quad$ REFERENCES .................... 71 
BITE Environmental Design Specifications BITE FEL Sensor Characteristics . . . . . . . 30 Safety Alerts .................. 51

Machine Performance Alerts .......... 53

Operator Performance Alerts ........... 54

Meter Mode Displays ............. 56

Personality Constants .............. 67

\section{LIST OF FIGURES}

$\underline{\text { Figure }}$

\section{Title}

Page

BITE System Block Diagram ............ 7

Keypad Mock-Up. . . . . . . . . . . . . 18 Display Mock-Up . . . . . . . . . . . . . 20

Microcomputer Block Diagram ............ 22

Signal Conditioner Block Diagralll . . . . . . . 26

Sound Level Characterization ............ 49

Histogram - Engine 0il Temperature ........ 60

Histogram - Engine Coolant Temperature ....... 61

Histogram - Engine RPM ............. 62

Maintenance Report ............. 63 


\subsection{EXECUTIVE SUMMARY}

The Built In Test Equipment (BITE) to Improve Front End Loader (FEL) Productivity contract was awarded in September 1980. Since that time McDonnell Douglas Electronics Company (MDEC) has completed the preliminary design task and has begun to fabricate and assemble a single breadboard system that will be ready for bench testing in August 1981. This report describes the breadboard system.

The preliminary design task consisted of reviewing previous Dept. of Energy reports, reviewing the stability indicator work being developed by the Bureau of Mines, reviewing FEL systems and applicable sensors, and conducting FEL tests to define the BITE environment.

The goal of the BITE system is to improve the availability and productivity of large FELs, 10 cubic yards and above. The approach being employed is to:

- Develop a cost effective base system, adaptable to various makes and sizes of FELs.

- Develop displays to improve operator safety and performance.

- Develop displays to alert the operator of servicing requirements and abuse of the FEL.

- Develop on-board maintenance and productivity displays.

- Develop maintenance reports for identifying and logging FEL problems and utilization. 
A BITE system block diagram is shown in figure 1. The components located in the FEL cab are a 32 character 1 iquid crystal display (LCD), 16 pushbutton keypad, FEL stability indicator display, and microcomputer. The signal conditioner is a separate box located in the hydraulic or engine compartment. Signal conditioner functions are to supply reference voltages to sensors and supply sensor data in digital form to the microcomputer. FEL sensors are located throughout the FEL. Sensors have been classified as machine parameter sensors or operation parameter sensors. The machine parameters monitor FEL subsystem performance. The operational parameters monitor FEL use.

The tape unit and printer are kept at the maintenance shop. The tape unit is portable and is taken to the FEL to get data. The maintenance report is a summary of operator messages that were issued since the last time that data was collected. 


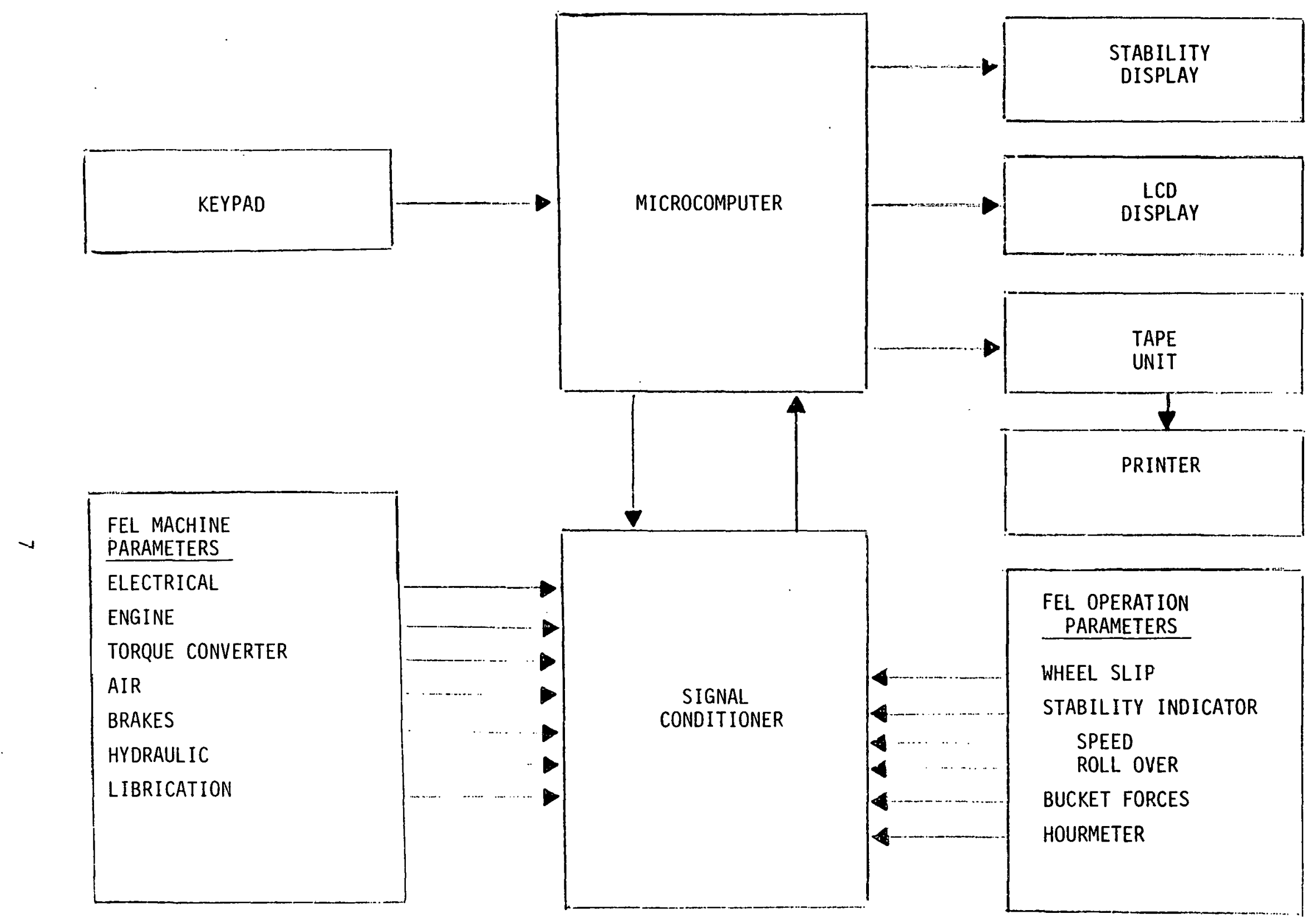

FIGURE 1

BITE SYSTEM BLOCK DIAGRAM 


\subsection{BITE HARDWARE}

The BITE system described in this report is the result of several background studies and evaluations that were performed. These included:

- Reviewed concepts developed by Skelly and Loy, Ref. 1, $2 \& 3$.

- Reviewed FEL stability indicator being developed by the Bureau of Mines.

- Inspected instrumentation displays and available space in the cabs of Caterpillar, Dart, John Deere, and LeTourneau machines.

- Reviewed common machine subsystems and monitoring devices.

- Reviewed methods of presenting information to the FEL operator and maintenance personnel.

- Conducted field tests to define the operating environment.

- Reviewed components, sensors, and technology applicable to a BITE system.

\subsection{Design Considerations}

The background studies led to the establishment of the BITE design considerations which includes the definition of the BITE operating environment, and how to package the system so that it can be maintained by mine maintenanre persunnel. 


\subsubsection{Environment}

A major area of concern for any electronic system is operating environment. FEL's operate under many environmental extremes throughout the coal producing regions of the United States. Temperature extremes, vibration, and electromagnetic compatibility are critical design parameters. The BITE environmental design specifications are listed in Table 1.

\section{Temperature}

Ambient temperature extremes can range from an over-night low of $-55^{\circ} \mathrm{C}$ in Northern climates to a high of $+55^{\circ} \mathrm{C}$ in the coal surface in Southern climates: Machine generated heat from normal operation also increases the total temperature that the system will be exposed to. To meet these extremes, when applicable militray grade components have been selected.

Commercial grade components typically have an operating temperature range of $0^{\circ} \mathrm{C}$ to $70^{\circ} \mathrm{C}$ and are packaged in plastic cases. Both the low temperature range and plastic case are unsuitable for the FEL environment. Hermetically sealed ceramic cased components must be used to protect against humidity problems.

The majority of military grade components are available only with a $-55^{\circ} \mathrm{C}$ to $125^{\circ} \mathrm{C}$ operating range. Some of the more expensive components such as the processor and math chips are available in two temperature ranges. To reduce costs, an operating range of $-55^{\circ} \mathrm{C}$ to $85^{\circ} \mathrm{C}$ is selected when available. 


\section{TABLE 1}

\section{BITE ENVIRONMENTAL DESIGN SPECIFICATIONS}

\section{Temperature}

Operating:

Non-Operating

Humidity

Maximum:

Condensation:

Frost:

Mechanical Shock

Magnitude

Waveshape

Vibration

Machine Frame

Bucket and Boom

Electromagnetic Interference

Conducted AC Voltage

Electric Field Inteensity

Transient Protection

Vol tage

Duration

Dust

Concentration

Mean Size $-40^{\circ} \mathrm{C}$ to $+85^{\circ} \mathrm{C}$

$-55^{\circ} \mathrm{C}$ to $+125^{\circ} \mathrm{C}$

$100 \%$ RH at $65^{\circ} \mathrm{C}$

Yes

Yes
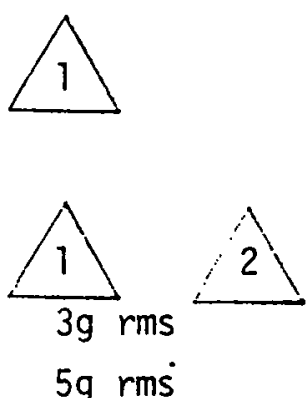

3 volts rms

20 Volts per meter

141 volts peak

$50 \mathrm{~ns}$ to 500 us

0.5 to 3 micruns

MDEC will perform test environment. surveys and mine field tests to define the environment.

2 MDEC interprets the vibration requirements to be random vibration with a flat spectrum from 5 to $500 \mathrm{~Hz}$ at the indicated overall acceleration levels. 
Vibration

Preliminary FEL shock and vibration data was obtained by instrumenting a 15 cubic yard Dart $600 \mathrm{C}$ loader operating at the factory test site. This was done primarily to verify instrumentation points and test procedures. Triaxial accelerometers were initially located on the FEL at the bucket pivot pin and the hydraulic bucket tilt ram. The tests were repeated with the accelerometers mounted on the floor and dashboard of the cab, and on the engine compartment.

Data was recorded for the following maneuvers:

Bucket tilt to stop

Empty bucket maximum lift rate to stop

Empty bucket dump

Empty bucket slam on ground

Complete load and unload of loose dirt

High engine RPM run

The maximum shock measured was $21.2 \mathrm{~g}$ for a duration of 40 milliseconds in the vertical direction at the bucket pivot pin when the empty bucket was slammed on the ground.

The following observations were made during the tests:

0 Most shock and vibration inputs originated at the bucket and boom structures and are greatly attenuated as they are transmitted to the cab and center pivot point. 
- Low level periodic vibration, originating from rotating machinery, was present at all accelerometer locations except the bucket pivot pin and hydraulic bucket tilt ram.

0 Spectrum analysis data revealed no significant response frequency above $50 \mathrm{HZ}$.

- The response data was basically shock transients with a long pulse duration that was initiated at the bucket.

- The maneuvers that extended the FEL bucket to the stops were probably as severe as can be expected at a mining operation.

- The pile of loose dirt was not representative of material that is normaliy loaded at a mining operation.

0 The ground terrain was not representative of an actual mining operation.

The tests will be repeated on a FEL removing overburden after the resolution of the Untted Mine Workers contract. 
Because EMI characteristics of large FELs could not be found in the literature or obtained from manufacturers, survey tests were conducted on a Dart $600 \mathrm{C}$ diesel-mechanical and a LeTourneau L700 diesel-electric machines. This data will be used to minimize the risk of electromagnetic incompatibility between FEL wiring and co-located BITE electronic units and cables. Digital circuits are particularly susceptible to upset from transients coupled to inputs of these circuits. Therefore, consideration was limited to measuring only the peak level of FEL transient emission. Conclusions reached from the experimental data are as follows:

- Transient voltages coupled from the electric-drive FEL are two orders of magnitude more intense than those coupled from the mechanical-drive FEL.

- The highest coupled transient voltages is 1.41 volts and occurs when engine start is initiated.

- Other than engine start, the highest coupled transient voltages occur when forward motion is initiated on the electric-drive FEL. The measured transients were 36 volts at the $D C$ cable on the left side of the cab and 125 volts at the $A C$ generator output cable. 
BITE circuits on an electric-drive FEL must be both shielded and common mode protected by the use of isolated signal loads or differential line receivers.

Cable shielding generally yields a minimum shielding effectiveness factor of about 100. With shielding alone, coupled transient voltages during engine start and the initiation of forward motion would exceed the 1.0 volt noise margin of single-ended digital circuits. Differential signal load circuitry will also be used. It generally provides a 15 volt noise immunity. 


\subsubsection{Maintenance}

Maintainability or the ease of maintenance has been defined as a significant BITE performance characteristic. The BITE maintenance philosophy is that the system will be capable of fault isolation to the defective subassembly and/or circuit module and replacement of the defective item by mine personnel. The following maintainability features have been established as design goals:

- The BITE system will not contain any devices that require scheduled maintenance. Typically, these are items such as filters, tape reader heads, rotating devices requiring periodic lubrication, etc.

- At "Power On", the BITE system will automatically perform a self diagnostics routine in order to determine the ability of the BITE to analyze the operational readiness of the front end loader. If there is a fault encountered with the condition of the BITE, this will be indicated in a display presentation, which is part of the BITE system. The display will also indicate which replaceable module is defective.

- A failure in the BITE system shall not impede operation of the front end loader.

o The mean time to repair (MTTR) of the BITE system shall not exceed one hour. 
- All electronic circuitry will be housed in environmentally sealed enclosures suitable for rugged environments. All input/output connections to the electronic enclosures will utilize environmentally sealed connectors.

- Circuits will be modularized so that failures can be fault isolated to a single circuit card. These cards will be designed as plug-in modules with attached cam-action extractors.

- Reference designators will be utilized on all circuit cards and their proper positions within the enclosure marked with a corresponding reference designator.

- All sensors will be either "discard at failure" type or can be repaired by replacement of a defective sensing element. 


\subsection{BITE Components}

The BITE system has six major subsystems: the keypad, display, microcomputer, signal conditioner, sensors, and maintenance report printer. The sensors have been classified according to function as machine parameters and operation parameters. The machine parameters monitor FEL subsystem functions. The operation parameters are a collection of parameters that monitor how the operator is utilizing the FEL.

\subsubsection{Keypad}

A mock-up of the breadboard keypad is shown in Figure 2. An internal circuit card protects against contact bounce and provides serial data transmission to the microcomputer.

The selected keypad is designed for use in adverse environments. The surface of the keypad is covered with a one-piece neoprene elastomer which seals out oils, grease, water, dust, and sand. The keypad is suitable for gloved hand operation. The performance specifications are:

$\begin{array}{ll}\text { Operating Temp: } & -30^{\circ} \mathrm{C} \text { to } 71^{\circ} \mathrm{C} \\ \text { Key Spacing: } & .75 \text { inch } \\ \text { Key Travel: } & .10 \text { inch } \\ \text { Operating Force: } & 15 \text { ounces nominal } \\ \text { Life: } & 500,000 \text { operations }\end{array}$




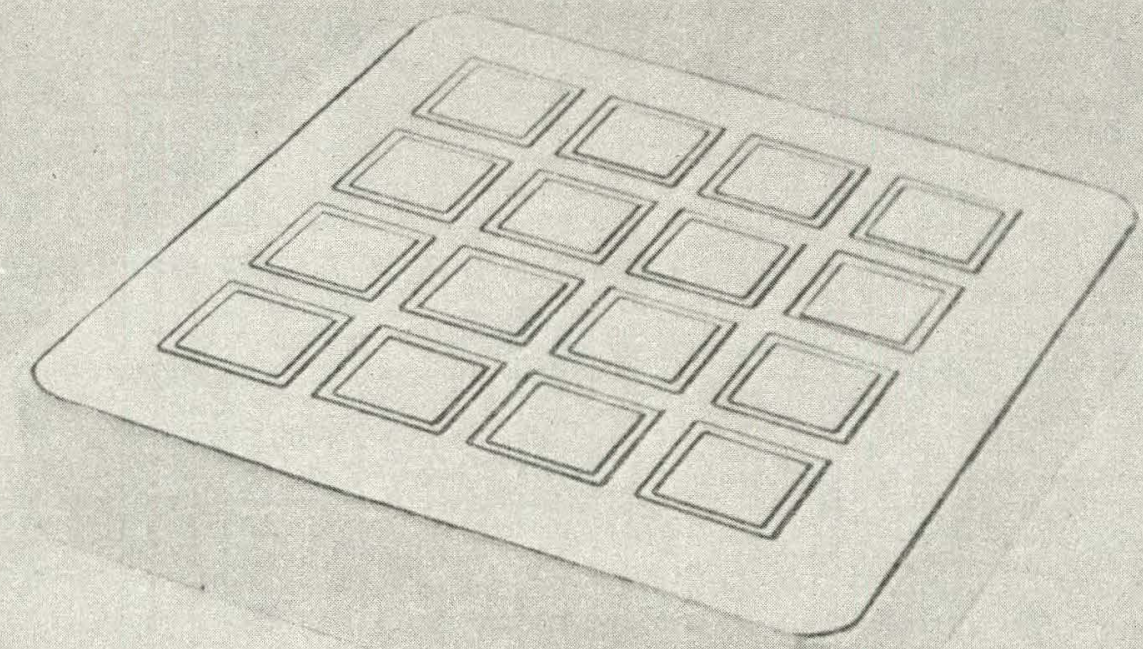

FIGURE ?

KEYPAD MOCK-UP

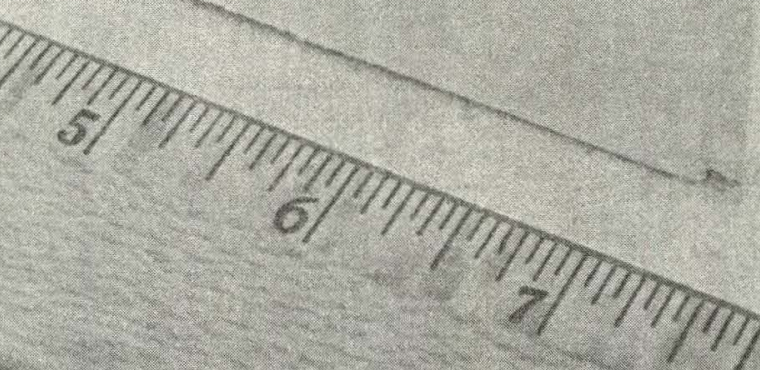




\subsubsection{Display}

A mock-up of the breadboard display is shown in Figure 3. The display has 32 characters arranged in two rows of 16 . Each character is .3 inches high and is presented in a $5 \times 7$ dot matrix format. Special characters and symbols are possible.

A liquid crystal display was selected because of their desirable characteristics of ultra low power consumption and high contrast ratio in bright sunlight. The unit is back lighted for night operation.

The operating temperature range of the $L C D$ is $-20^{\circ} \mathrm{C}$ to $70^{\circ} \mathrm{C}$. The low temperature limit will be extended by the use of display heaters. Display response times will be very slow until the display warms up.

\subsubsection{Microcomputer}

The microcomputer will monitor the FEL subsystems, provide the operator with status information, and generate data for hard copy reports. The microcomputer is based on the 28002 microprocessor. This is a 16-bit device capable of executing byte as well as word instructions. A sixteen-bit processor was chosen for several reasons. MDEC experience with the Dragline Information Gathering System (DIGS) has shown that a system whose main function is to gather and display information must have greater processing power and higher throughput than one that is merely collecting data. Also, since the software will evolve continuously to meet ever-changing customer requirements, programming must be done in a high-level language. A real-time application using a high-level language requires powerful and flexible processor. The Z8002 was selected after examination of the available processors and was 


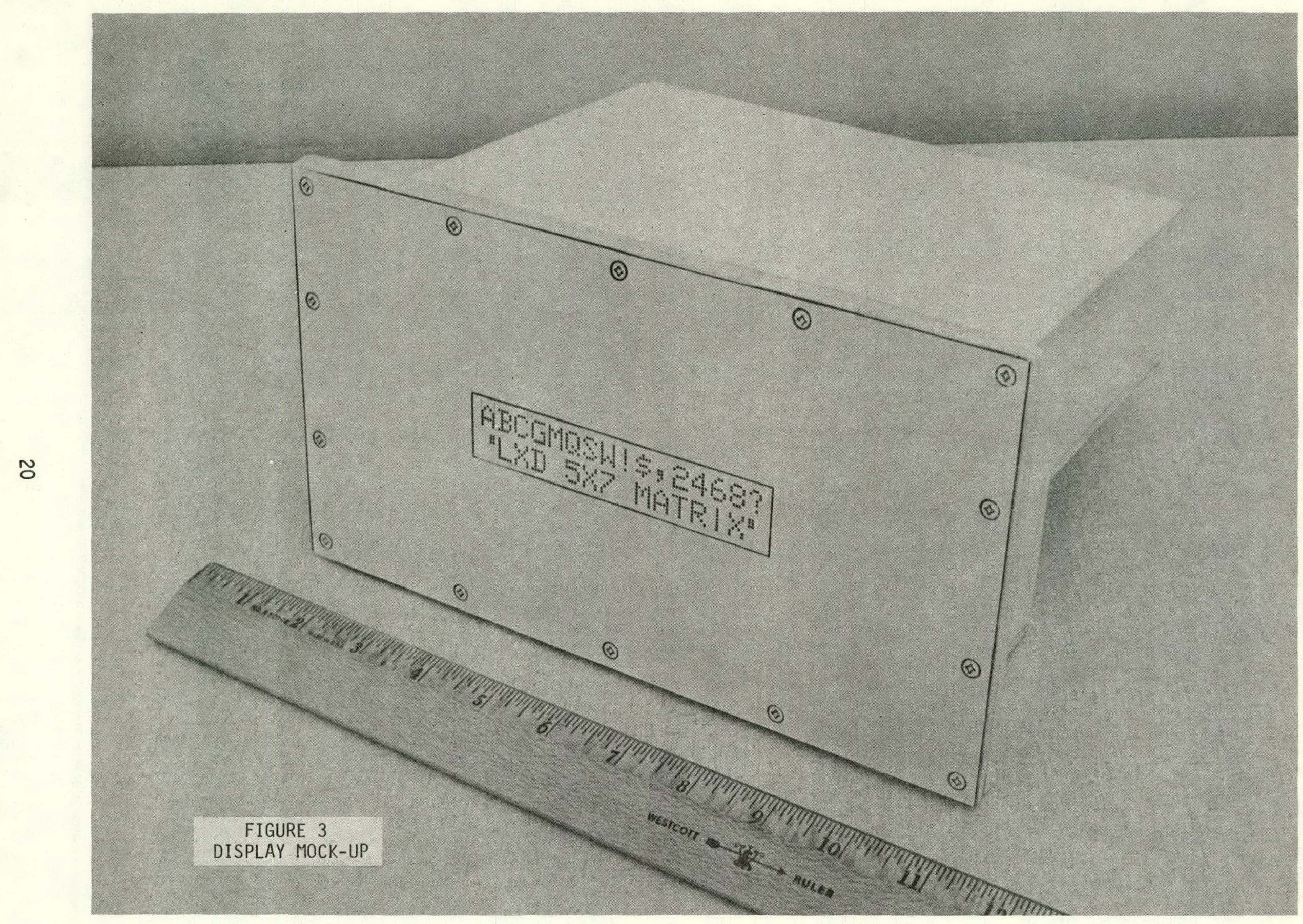


deemed best able to fulfill the above requirements in a mining environment. A preitiminary block diagram of the microcomputer is shown in Figure 4 . The system is organized around the Zilog Z-Bus Interconnect.

Memory will be composed of $8 \mathrm{~K}$ words of random access memory (RAM) and $16 \mathrm{~K}$ words of erasable-programmable read only memory (EPROM). An additional 4K words of RAM will be battery-powered when system power is off to retain data. These allocations are preliminary and provisions have been made to allow increasing or decreasing quantities of different types of memory as required.

An additional 1024 word memory will be placed in the input/output $(I / 0)$ address space for the purpose of holding the machine personality constants required to "fine-tune" the BITE system to a particular FEL. This memory will consist of a part that is actually two memories in one. To the rest of the system, it appears to be a RAM, but that RAM is actually backed up by an electrically erasable PROM (EEPROM). The contents of the RAM may be written into or read from the EEPROM at will. The device requires a single 5 volt supply and is ideally suited to storing parameters that are essentially permanent but may need occasional updating. Battery back-up would be impractical here because the constants could be lost and have to be re-entered when the battery is replaced or if it is allowed to discharge. 


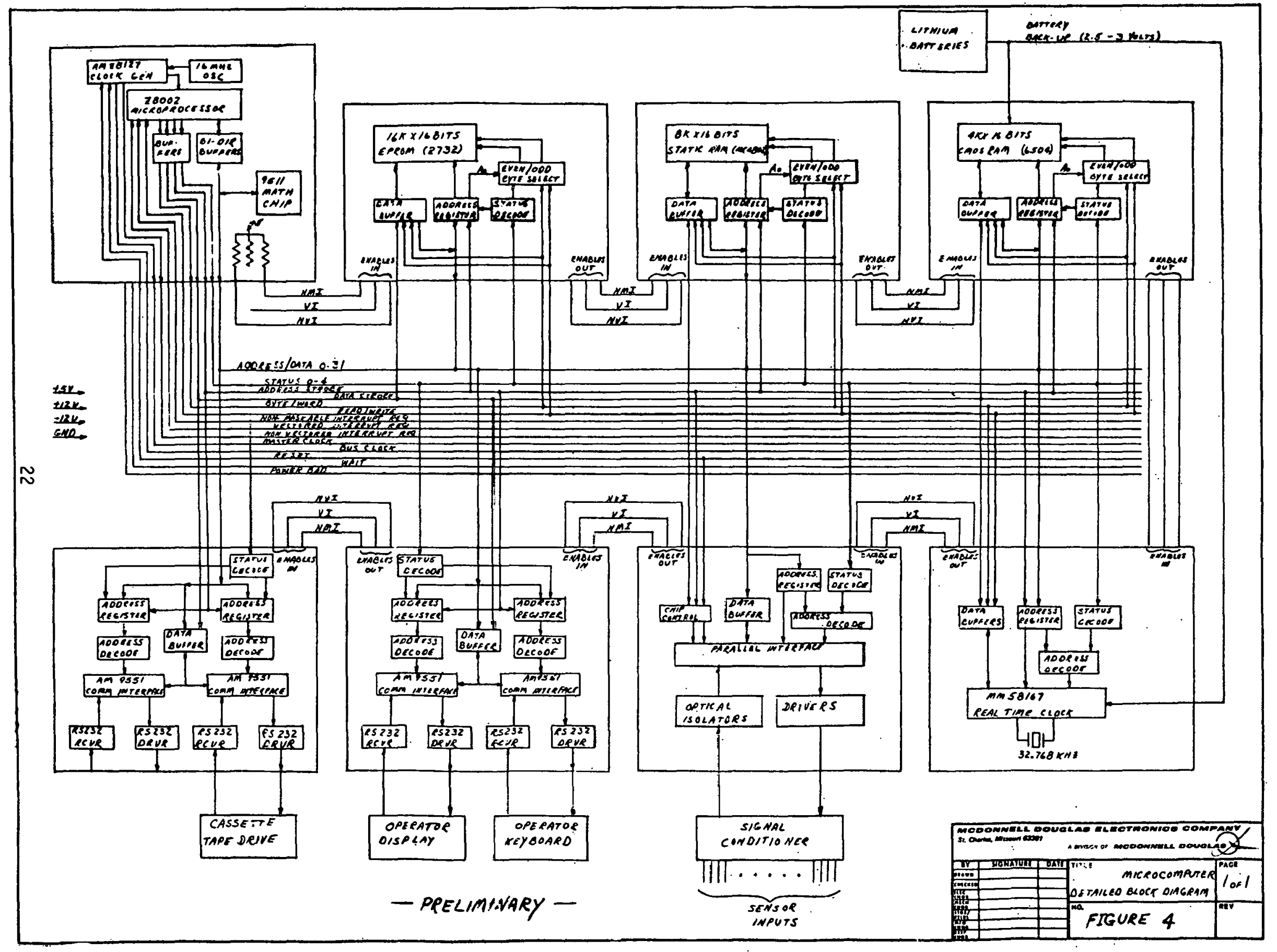


A real time clock is incorporated that keeps track of time down to thousandths of seconds. It can generate interrupts as fast as every tenth of a second which the processor can use as a real base for checking data acquisition registers. The clock will also be backed up by a battery so that it will continue running even when the rest of the system is not in operation.

Lithium batteries have been chosen for the real time clock and battery backup RAM circuits because of their high terminal voltage and high energy density. These devices have a 2.8 to 3 volt output and have a very flat discharge characteristic. Being non-rechargeable, when they reach 2 volts they are considered dead. They have a wider operating temperature range $\left(-54^{\circ} \mathrm{C}\right.$ to $\left.74^{\circ} \mathrm{C}\right)$ than almost any other battery. As an example of their energy density, a D-size lithium battery has the capacity to power the $4 \mathrm{~K}$ words of memory and the real time clock continuously for one year. Since the battery is to serve as a back-up function to a system power supply, 1 ife expectancy will be on the order of three years.

Parallel communication will be used to handle data interchange with the signal conditioner. The signal conditioner is that portion of the BITE system which will interface with the FEL and perform analog to digital conversion, detect discrete switch position and count pulse trains from proximity sensors mounted on the machine's axles. The parallel interface will provide separate 16-bit input and output ports. Optical isolation will be used at the receiver ends of the parallel cables to prevent potentially damaging voltages from being conducted into the processor enclosure. 
Serial input and output data will be via an RS-232C compatible interface. A programmable communication interface circuit will provide modem control so that each port can provide a full RS-232C implementation or data transmission and reception portions of the standard. Serial I/0 will be used to communicate with the operator display and keypad. In addition, communication will be possible with a variety of terminals, a modem, or any device compatible with RS-232C. 


\subsubsection{Signal Conditioner}

The signal conditioner interfaces the FEL subsystem sensors to the microcomputer. It provides excitation and reference signals to the sensors, provides electrical isolation from the FEL power and ground system, converts. the sensor signals to digital format and transmits the data to the microcomputer.

The possibility of purchasing commercial units such as the Micro Mac 4000 Series built by Analog Devices and Sinealab were investigated. The units were too expensive $(\$ 8,000)$, provided extra features that would not be utilized, and were not desianed for operation in a mining environment. The decision was made to design a signal conditioner that is expanded by picking and choosina the required number of functional circuit cards. The signal conditioner uses independent multiplex bux system to minimize the cables between the conditioner and microcomputer.

Five circuit cards have been designed to interface temperature, pressure, position, force, speed, and stress signals. Optical isolation is used between the circuit cards and FEL sensors to prevent potentially high voltages from damaging the signal conditioner. A block diagram of the system is shown in Figure 5 . 


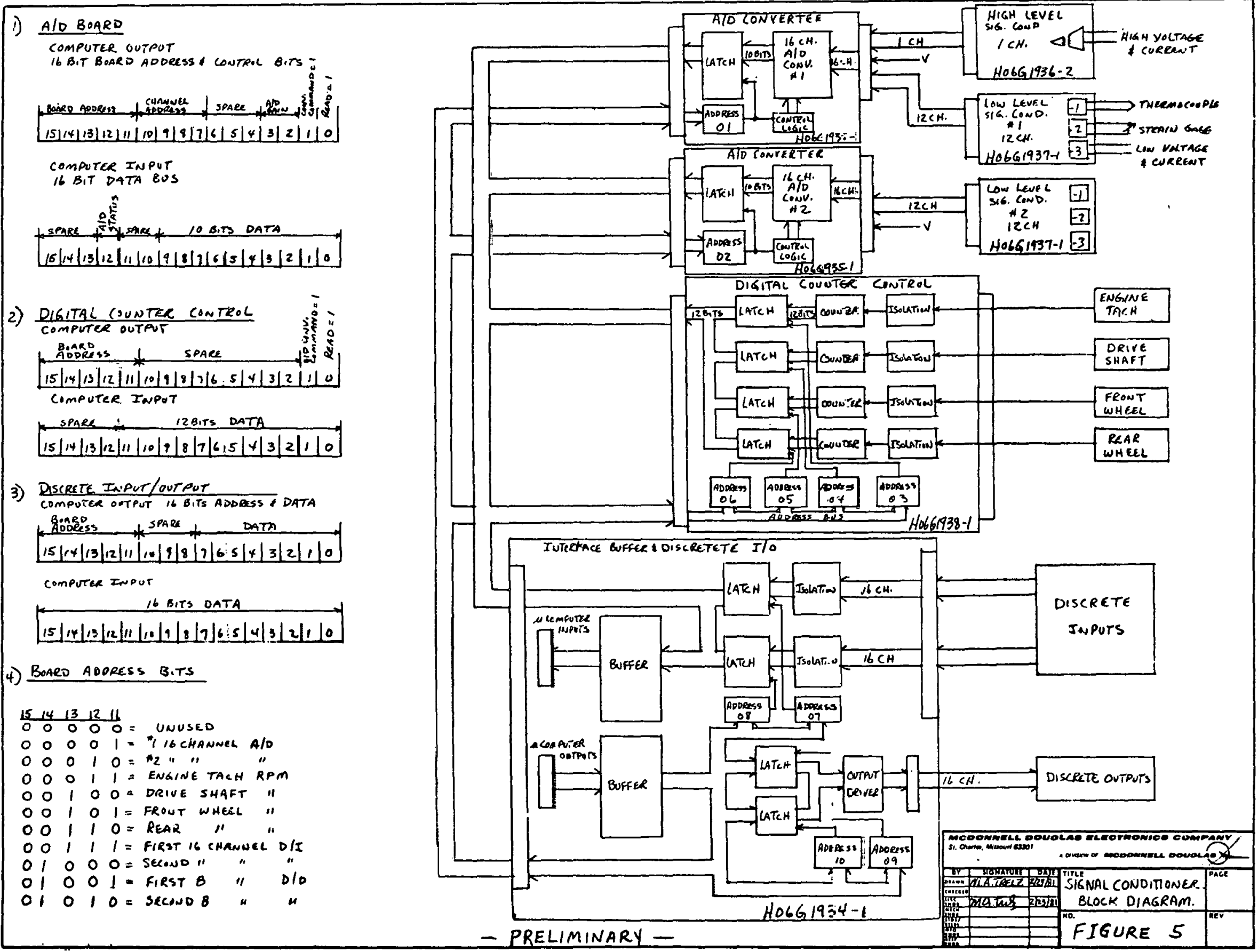


The Interface Buffer and Discrete Input/Output circuit board interfaces the microcomputer to the signal conditioner system by means of sixteen (16) parallel input and sixteen (16) parallel output data lines. After buffering,

- the input/output data lines are distributed through the circuit board and bussed to the backplane as the signal conditioner bus. This card can accept thirty-two (32) input discretes and provide sixteen (16) output discretes to - interface external circuits.

The digital counter circuit board contains three counter circuits consisting of address control, input latch, digital counter, and input sensor isolation circuits. The three counter control circuits will receive digital count pulses from sensors on the engine output drive shaft, one rear wheel axle, and one front wheel axle. The microcomputer will address each counter in succession and read the accumulated counts. When the address lines are decoded to read the counter information the address pulse is delayed and used to reset the counter to make ready for the next series of sensor input pulses. 
The analog to digital $(A / D)$ converter circuit board consists of four parts. The address control, the output latch, the convert command control, and the converter module. The $A / D$ converter has sixteen input channels which are multiplexed and addressed in succession onto the signal conditioner bus through the output latch.

The Low Level Signal Conditioner will contain all necessary circuitry to interface parameters from sensor such as, pressure; temperature, force, stress, angular, and acceleration. This circuit board will not be connected to the data bus. All output will be routed to the analog input converter. The circuit sonfiguration will have five (5) analog potentiometer signal conditioners, twelve (12) analog bridge signal conditioners, one (1) AC bridge signal conditioner, and the 1OVDC bridge excitation reference. The circuit will continuously output present data to the $A / D$ converter for transfer to the microcomputer.

The High Level Signal Conditioner circuit board will contain all voltage inputs greater than 5VDC and can handle voltage up to 1000 VUC. Because of the possibility of high voltage existing on this device, the circuit card will be isolated from the signal conditioner chassis and contained in a safe enclosure of its own. The output will be scaled to \pm 5 VDC maximum signal and routed to the $A / D$ converter for transfer to the microcomputer. 


\subsubsection{Machine Parameters}

Machine parameters will be monitored by sensors located in the major FEL subsystems such as the electrical, engine, torque converter, air brakes, hydraulic, lubrication, and nitrogen systems. Existing FEL sensors are used whenever possibe. Many signals are already available at terminal board locations.

Table 2 identifies the sensors used by each major system. The table identifies existing FEL sensors, type of signal, the sensor range, and the warning sense point. The operating ranges and warning sense points were established by consultation with manufacturers and review of FEL manuals. The warning sense points are stored in the personality module so they can be adjusted for different machines.

\section{ELECTRICAL SYSTEM}

The following electrical system sensor will be added: Battery voltage level

The battery voltage level will be used to verify that the charging system is operating. The normal charging range is 27.5 to 28.0 volts. Over voltage and under voltage machine performance alerts will be issued if the battery voltage is out of range when the engine is running. If the battery drops below 22.0 volts, a low battery alert will be issued. The number of occurrences of each malfunction will be printed on the maintenance report. 
TABLE 2

BITE FEL SENSOR CHARACTEPIST:CS

$\begin{array}{ll} & \text { SENSOR } \\ \text { SENSOR } & \text { SIGNAL }\end{array}$

SIGNAL

WARNING

MANUFACTURER RANGE

TYPE

SENSE

ELECTRISAL SYSTEM:

Battery Voltage

0-30V DC

Analog

$<22 V D C$

ENGINE:

Speed

$0 i 1$ Press

Coolent Temp

Fuel Press

Air Filter Press

$\begin{array}{ll}2400 \text { RPM } & \text { Digital } \\ 0-200 \text { PSI } & \text { Analog } \\ 0-250^{\circ} \mathrm{F} & \text { Analog } \\ & \text { Discrete } \\ & \text { Discrete }\end{array}$

$\omega$

TORQUE CONVERTER:

0 i 1 Temp

AIR SYSTEM:

Main Tank Press

BRAKE SYSTEM:

Fron: Brake

Malfunction

Rear Brake

Malfunction

Parking Brake On

Emergency Brake on
Yes

$100-300^{0} \mathrm{~F}$

Analog

$>275^{\circ} \mathrm{F}$

$0-200$ PSI

Analog

$\angle 85$ PSI

Yes

Yes

Yes

Yes
Differenti $\equiv 1 \quad$ Discrete $\triangle 200 \mathrm{PSI}$

Differential Discrete $\triangle 200 \mathrm{PSI}$
Discrete

Discrete 
TABLE 2. (Continued)

BITE FEL SENSOR CHARACTERISTICS

\begin{tabular}{|c|c|c|c|c|}
\hline PARAMETER & $\begin{array}{l}\text { MANUFACTURER } \\
\text { INSTALLED } \\
\end{array}$ & $\begin{array}{l}\text { SENSOR } \\
\text { RANGE }\end{array}$ & $\begin{array}{c}\text { SENSOR } \\
\text { SIGNAL } \\
\text { TYPE } \\
\end{array}$ & $\begin{array}{c}\text { WARNING } \\
\text { SENSE } \\
\text { POINT } \\
\end{array}$ \\
\hline \multicolumn{5}{|l|}{ HYDRAULIC SYSTEMS: } \\
\hline Reservcir Filter & Yes & Differential & Discrete & 15 PSI \\
\hline Reservair Level & Yes & & Discrete & Factory Set \\
\hline Reservair Temp & Yes & $0-250^{\circ} \mathrm{F}$ & Discrete & $>200^{\circ} \mathrm{F}$ \\
\hline $\begin{array}{l}\text { Pump \#1 Case Temp } \\
\text { Pump \#2 Case Temp }\end{array}$ & & $\begin{array}{l}0-250^{\circ} \mathrm{F} \\
0-250^{\circ} \mathrm{F}\end{array}$ & $\begin{array}{l}\text { Discrete } \\
\text { Discrete }\end{array}$ & $\begin{array}{r}>200^{\circ}-225^{\circ} \mathrm{F} \\
\text { Adjustable }\end{array}$ \\
\hline Pump \#3 Case Temp & & $0-250^{\circ} \mathrm{F}$ & Analog & \\
\hline Particle Detectors & & & Discrete & \\
\hline $0 i 1$ Cooler Input Press & & $0-100 P S I$ & Discrete & $<50$ PSI \\
\hline 0it Cooler Flow & & $0-130 \mathrm{GPM}$ & Discrete & $<40$ GPM \\
\hline 0il Cosler Output Temp & & $0-250^{\circ} \mathrm{F}$ & Analog & $>180^{\circ} \mathrm{F}$ \\
\hline Lift Cyclinder Temp - Right & & $0-250^{\circ} \mathrm{F}$ & Analog & $\Delta 15^{\circ} \mathrm{F}$ \\
\hline Lift Cyclinder Temp - Left & & $0-250^{\circ} \mathrm{F}$ & Analog & $\triangle 15^{\circ} \mathrm{F}$ \\
\hline \multicolumn{5}{|l|}{ LUBRICATION: } \\
\hline Lube Solenoid & Yes & $\begin{array}{l}\text { Time } \\
\text { Adjustable }\end{array}$ & Discrete & $\begin{array}{l}\text { At lease every } \\
80 \text { minutes }\end{array}$ \\
\hline \multicolumn{5}{|l|}{ NITROGEN SYSTEM: } \\
\hline Oil Refill & & $0-6^{\prime \prime}$ & Discrete & $>6^{\prime \prime}$ \\
\hline 0it Press & & $0-3000$ PSI & Discrete & $<1500$ PSI \\
\hline
\end{tabular}


TABLE 2 (Continued)

\section{BITE FEL SENSOR CHARACTERIST-CS}

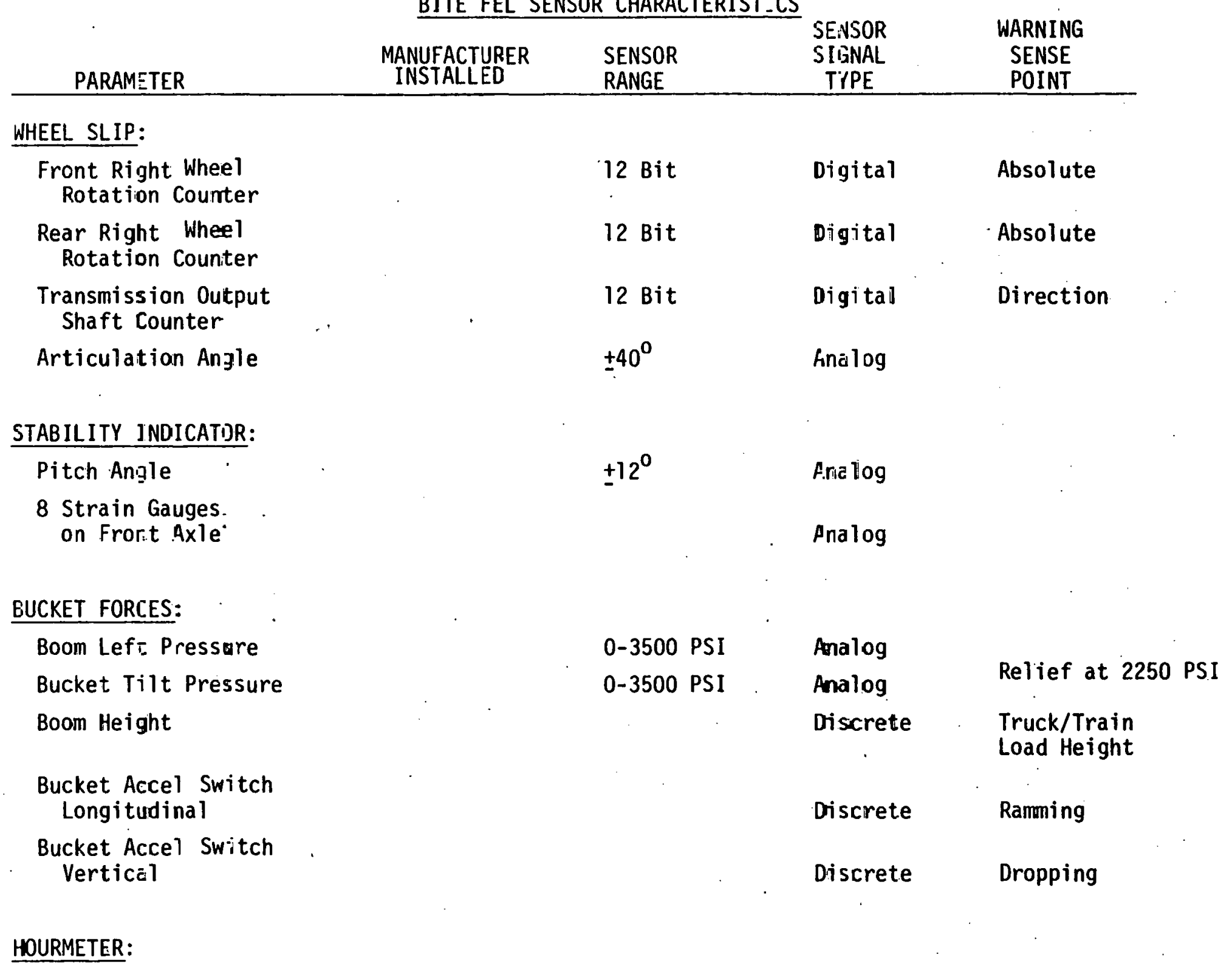

Calculated from existing sensor information. 


\section{ENGINE}

The following engine sensors will be added:

Engine speed

0i1 Pressure

Coolant Temperature

Fuel pressure

Air filter pressure switch

Engine oil pressure and engine RPM will be monitored. If the oil pressure is below an established value when the engine speed is above 1500 RPM, a machine performance alert will be issued. Checking the engine RPM eliminates spurious alerts at low engine speeds. This is most likely to occur in late summer when it is very hot. The number of occurrences and the time of the first occurrence will be printed on the maintenance report.

The minimum oil pressure limit will be established by consulting with the engine manufacturer. The engine RPM will be obtained by the addition of a magnetic pickup sensor.

Normal engine coolant temperature is in the range of $170^{\circ}$ to $185^{\circ} \mathrm{F}$. When the temperature reaches $200^{\circ} \mathrm{F}$ a machine performance alert will be issued. The number of occurrences will be printed on the maintenance report. 
A positive pressure switch will be installed between the engine and fuel filter. A loss of pressure indicates that the filter needs replacing or that there is a fuel leak. A machine performance alert will be issued. The time of occurrence will be printed on the maintenance report.

The air pressure across the engine air filter will be monitored to determine when the filter needs cleaning or replacing. A machine performance alert will be issued when the pressure exceeds an established value. The time of the alert will be printed on the maintenance report.

TORQUE CONVERTER

The following existing torque converter sensor will be used:

Converter oil temperature

The normal torque converter oil temperature range is $180^{\circ}$ to $225^{\circ} \mathrm{F}$. If the temperature reaches $275^{\circ} \mathrm{F}$ a performance alert will be issued. The number of occurrences and the time of the first occurrence will be printed on the maintenance report.

\section{AIR SYSTEM}

The following air system sensor will be added:

Main air tank press indicator 
The main air tank pressure sensor will issue govenor adjustment and air leak performance alerts. When the engine is running, the air pressure should be between 95 and 120 PSI. The average upper and lower tank pressures will be printed on the maintenance report.

Air leaks will be detected by a slow air pressure rise or if the pressure never reaches 100 PSI when the engine is started. The pressure recovery rate should be greater than 6 PSI per minute. A rapid pressure drop. when the engine is shut off will also indicate leaks. This requires a BITE shutdown delay. The existence of a leak will be identified in the maintenance report.

A safety alert will be issued if the air pressure drops below 85 PSI during normal FEL operation. This is the point at which the wig-wag drops into view. The display will indicate STOP USE EMER BRAKE. The number of occurrences and the time of the first occurrence will be printed on the maintenance report.

\section{BRAKE SYSTEM}

The following existing brake system signals will be used:

Front brake malfunction switch

Rear brake malfunction switch

Parking brake ON switch

Emergency brake ON switch 
The brake malfunction switches will alert the operator that an unsafe operating condition exists. The number of occurrences and the time of the first occurrence will be printed on the maintenance report.

An operator safety alert will be issued if the engine is turned OFF and the parking brake is not engaged. This requires delaying the BITE system shutdown until the parking brake is set.

HYDRAULIC SYSTEMS

The hydraulic system has been subdivided into three systems, the reservoir, the pumps, and the steering.

HYDRAULIC RESERVOIR - The following existing reservoir sensors will be used:

Filter pressure switch

Reservoir level switch

Reservoir temperature switch

The filter pressure switch will signal that it is time to replace the 10 micron filters. The level switch indicates that the reservoir needs filling. The temperature switch indicates that oil temperature has exceeded $200^{\circ} \mathrm{F}$, the machine should be stopped, cause located and corrected. 
Machine performance alerts will be issued for each of the above conditions. The number of occurrences and the time of the first occurrence will be printed on the maintenance report.

HYDRAULIC PUMPS - The following hydraulic pump sensors will be added:

Pump case temperature switch

Pump case temperature

Particle detectors

Pump case temperatures will be monitored to determine over temp conditions which indicate pump problems. Adjustable temperature switches will be used on two pumps. The final temperature settings will be established during the field evaluation. The third pump will have an analog sensor to collect design data. which will be reported in histogram format. Over temperature conditions will issue a machine performance alert. The number of occurrences and the time of the first occurrence will be printed on the maintenance report.

The development of a magnetic hydraulic oil particle detector is being investigated. The present concept would use a magnetized sensor that contains two electrodes separated by a calibrated gap. As the magnetic particles are deposited, a conductive bridge would be built between the electrodes. When the gap closes, a machine performance alert would be issued and the time of the occurrence would be printed on the maintenance report. The detector will have a thread mounting and can be removed for cleaning. 
It is anticipated that approximately five particle detectors would be placed on the FEL. Parts for laboratory testing and development have been ordered.

HYDRAULIC STEERING - The following hydraulic steering system sensors will be added:

0i1 cooler input pressure

0il cooler flow switch

0il cooler output temperature

The oil cooler input pressure switch indicates that the steering system is pressurized. A loss of pressure will issue a safety alert. The number of occurrences and the time of the first occurrence will be printed on the maintenance report.

The oil cooler flow switch indicates a loss of steering pressure or a clogged or restricted cooler. This check will not be made if there is a loss of steering pressure. When the oil flow drops below 40 gallons per minute, a machine performance alert will be issued. The number of occurrences and the time of the first occurrence will be printed on the maintenance report.

The oil cooler output temperature will be reported in histogram format. A machine performance alert will be issued when the oil temperature exceeds $180^{\circ} \mathrm{F}$. The number of occurrences and the time of the first occurrence will be printed on the maintenance report. . 


\section{LUBRICATION}

The following existing Lincoln Lube system signal will be used:

Lube solenoid signal

The lube system time interval is adjustable. BITE will monitor the solenoid signal to verify that the lube system is functioning on schedule. The BITE time constant will be stored in the personality module and adjusted to be slightly larger than the lube system time interval. A machine performance alert will be issued and the message PRESS LUBE SW will be displayed when the lube system fails to operate.

The possibility of adding a lube level sensor to assure that lubrication is available is being investigated.

\section{NITROGEN SYSTEM}

The nitrogen or balanced boom system is a Dart specific system that functions as a counter balance to assist the conventional load raising mechanism of the front end loader. The following balanced boom sensors will be added:

0il refill signal,

0i1 pressure switch

The oil refill switch indicates that the hydraulic oil needs to be recharged. When the oil pressure switch indicates that the pressure has dropped to 1500 PSI, the nitrogen system needs charging. Occurrences of either condition will issue a machine performance alert and the time of occurrence will be printed on the maintenance report. 


\subsubsection{Operation Parameters}

The operation parameters monitor how the operator is utilizing the machine. Additional sensors are added to the FEL to monitor wheel slip, speed stability, roll-over stability, bucket forces; and an hour meter.

\section{WHEEL SPIN}

The wheel spin monitor is intended to help reduce tire wear. The following sensors will be added:

Front wheel rotation counter

Rear wheel rotation counter

Transmission output shaft counter

Steering articulation angle

The rotation counters will be proximity type sensors. The wheel counters are absolute speed counters, they do not determine direction. The transmission shaft counter will include an additional sensor to determine the forward or reverse direction. The signal conditioner will accumulate the speed counts in sejparate registers which can be interrogated by the software. Following each interrogation the registers will be reset and begin accumulating counts again.

The maximum allowable wheel slip, the allowable speed difference betwean the left and right wheels without spinning, is calculated using the steering articulation angle. The rclative wheel slip for each axle is the difference between the fastest and slowest wheel. The relative wheel slip is compared to the maximum allowable slip to determine if a wheel is spinning. If both 
wheels are spinning on one axie and only one wheel is spinning on the other axle the maximum relative wheel slip will be between the non-slipping wheel and the other wheel on the axle.

The ground speed will be assigned to the speed of the slowest wheel. This calculated ground speed is also used by the speed stability system.

When wheel spinning is detected, an operator performance alert will be issued. The number of occurrences will be printed on the maintenance report. The wheel spin duration times will be accumulated and reported in histogram format.

This wheel spin monitoring system has the potential of being expanded into an automatic differential lock system. This system would automatically convert to a positraction drive when wheel spin is detected.

\section{STABILITY INDICATOR}

The stability indicator will function as both a warning device and training aid. As a warning device, the stability indicator will indicate that the FEL is approaching an unstable condition via a blue, green, yellow, and red indicator lights located in the operator's forward field of vision where it can be readily seen. The operator cannot take the time to look down at the LCD to discern the warning. The effect of the four.lights is to give the operator an indication of the rate at which he is approaching a critical rollover or overspeed situation. The trip points will be stored in the BITE personality module so that they can be adjusted for different machines and during field trials. The display indicator lights will be dimmable for night operations. 
As a training device, the stability indicator will provide inexperienced FEL operators with a visual indication of machine stability which they can associate with their seat of the pants feeling. At the present time, the only thing the operator knows is that he did not have any problem before, therefore he can push the machine just a little bit further. Through this process each operator establishes an operating envelop in which he feels comfortable. The stability indicator will establish a standard stability envelop for all operators and should reduce the time it takes the inexperienced operator to approach the safe operating limits.

\section{SPEED STABILITY}

This system will monitor the down hill grade, the bucket load, and ground speed. Some manufacturers mount caution placards in the cab which specify maximum safe operating speeds for different down hill grades. These machines have speedometers, not all machines do.

Unless someone tells the operator what grades he will encounter, he must make his own best guess and plan his speed accordingly. A typical placard indicates the following:

\begin{tabular}{|c|c|c|}
\hline \multirow{2}{*}{$\begin{array}{c}\text { Percent } \\
\text { Grade }\end{array}$} & \multicolumn{2}{|c|}{ Miles Per Hour } \\
\hline & Empty & Loaded \\
\hline 4 & 17 & 17 \\
\hline 8 & 16 & 14 \\
\hline 12 & 12 & 9.5 \\
\hline 16 & 8 & 6.5 \\
\hline 20 & 6 & 6 \\
\hline
\end{tabular}


The speed stability display will indicate the percentage of maximum safe operating speed as shown below:

\begin{tabular}{lc} 
Warning Light & \multicolumn{2}{c}{$\begin{array}{c}\text { Percentage } \\
\text { Red }\end{array}$} & 100 \\
\cline { 2 - 2 } Yellow & 75 \\
Green & 50 \\
Blue & 25
\end{tabular}

\begin{abstract}
A histogram will be used to monitor and evaluate the speed stability indicator. The histogram will count the times that each threshold setting is exceeded.
\end{abstract}

\title{
ROLL OVER STABILITY
}

This system will employ a modified version of the Zero Wheel Load Detector developed by Stevens. Institute of Technology under BOM Contract H0357114. This system uses strain gauges mounted on the front axle near each wheel to measure the normal load on the wheels. The basic principle is that the normal load on the upslope wheel decreases as the roll angle increases and finally becomes zero as the PEL rolls over.

Four strain gauges will be located on each axle wheel stub. The strain gauges will be mounted in two vertical planes. Each plane has one gauge on top of the axle and one gage on the bottom of the axle. By subtracting the moments between the planes, the side force component is eliminated and only the normal wheel force remains. The different cross-sections on tapered axle housing can 
be compensated for by adjusting the moment scalings.

The initial trip points for the display indicator lights are shown below:

Warning Light

Red

Yellow

Green

Blue

\section{Roll Angle}

$22^{\circ}$

190

$15^{\circ}$

$10^{\circ}$

A histogram will be used to monitor and evaluate the roll over protection operation. The histogram will count the times that each threshold seeting is exceeded.

\section{BUCKET FORCES}

The bucket forces will be monitored to determine bucket load and operator abuse of the machine. The following bucket force sensors will be added:

Boom lift pressure

Bucket tilt pressure

Boom height switch

Bucket acceleration switch - longitudinal

Bucket acceleration switch - vertical

The boom lift and bucket tilt hydraulic pressures will be monitored to estimate the bucket load. The boom height switch will indicate when to estimate the bucket weight. The weight will be estimated on the fly as the bucket is being lifted. The switch will be adjusted to be activated 
only when the bucket is raised to a truck or unit train loading operations. The number of bucket loads will be counted and reported on the maintenance report.

It is planned to mount accelerometer switches near the boom bucket pivot point. The longitudinal signal along with ground speed will indicate bucket shock due to ramming a stock pile. The vertical signal will indicate bucket shock due to slamming the bucket on the ground. Detection signal will issue an operator performance alert and the number of occurrences will be printed on the maintenance report. Predetermined levels will be established by instrumenting a FEL removing overburden.

The boom lift and bucket tilt hydraulic pressures will be monitored 10 times per second to monitor hydrautic spikes induced by bucket shock in an effort to possibly eliminate use of the accelerometers.

\section{Hourmeter}

The BITE hourmeter obtains its information from the engine speed sensor and the microcomputer clock. Three hourmeters will be maintained. The first indicates the time since the last data dump. The second hourmeter accumulates time whenever the engine is turning over. The third hourmeter will accumulate the time that the engine operates at high idle. These times will be printed on the maintenance report. 
2.7 Maintenance Report Printer

The maintenance report data accumulated by the BITE system is preformatted for printing, and retained in the microcomputer battery backed uP RAM. Maintenance personnel will transfer the data onto a portable tape recorder which is taken to the maintenance shop for printing.

The specific tape recorder and printer to be used have not been selected. The possibility of using a Radio Shack TRS-80 computer system will be investigated. This system offers the advantages of a maintenance shop computer with display capabilities at a cost that is competitive with buying an intelligent tape deck and printer.

46 


\subsection{BITE OPERATION}

The BITE system has three major operational modes, the power-up self test, the operator displays, and the maintenance reports.

\subsection{Power-Up Self Test}

When power is initially applied to the BITE computer, the computer will automatically execute a self test diagnostic. The system will check signal continuity to the keyboard, display, and signal conditioner. During the initial power-up sequence, a message will be put out to the display telling the operator of the power up test. If the display is inoperative the message or what is left of it will remain to inform the operator that the display is not functioning. Communication to and from the keyboard will be tested and if it has failed a message will be sent to the display. Communications to and from the signal conditioner will also be tested and a message will be put on the display if it fails.

The operator will not be required to do anything for the power up self test diagnostic. All of the boards in the processor box will be checked for bus connection through an I/O board address and answer back routine. After completion of the self test diagnostic, the system will automatically perform the BITE functions. 
The display will be tested by sending a message to the display and 3 seconds later the display will be requested to echo back that message.

The keyboard will be checked by sending a string of characters and the string will be echoed back to check against the original string.

The signal conditioner box boards will be checked for bus connection with a scheme similar to the processor box. The analog to digital converter and five volt power supply will be tested by running the five volts through the signal conditioner and checking the results against the acceptable range.

\subsection{Operator Displays}

The BITE information presented to the operator has been prioritized in descending order as alerts, meter mode displays, and maintenance displays.

\section{Alerts}

The BITE system monitors sensor data to generate safety, machine performance, and operator performance alerts. The alerts are prioritized such that a safety alert inhibits the machine and operator performance alerts, and a machine performance alert inhibits operator performance alerts.

Each type of alert is annunciated by separate distinctive audio signals. To avoid being masked by ambient FEL noise, the hasic frequency of the audio tone will be $2900 \pm 500 \mathrm{HZ}$ with an intensity of $68-80$. DB. The ambient noise level in a FEL cab was measured and is shown in Figure 6. . In addition to the audio annunciation, a descriptive message will be displayed. 


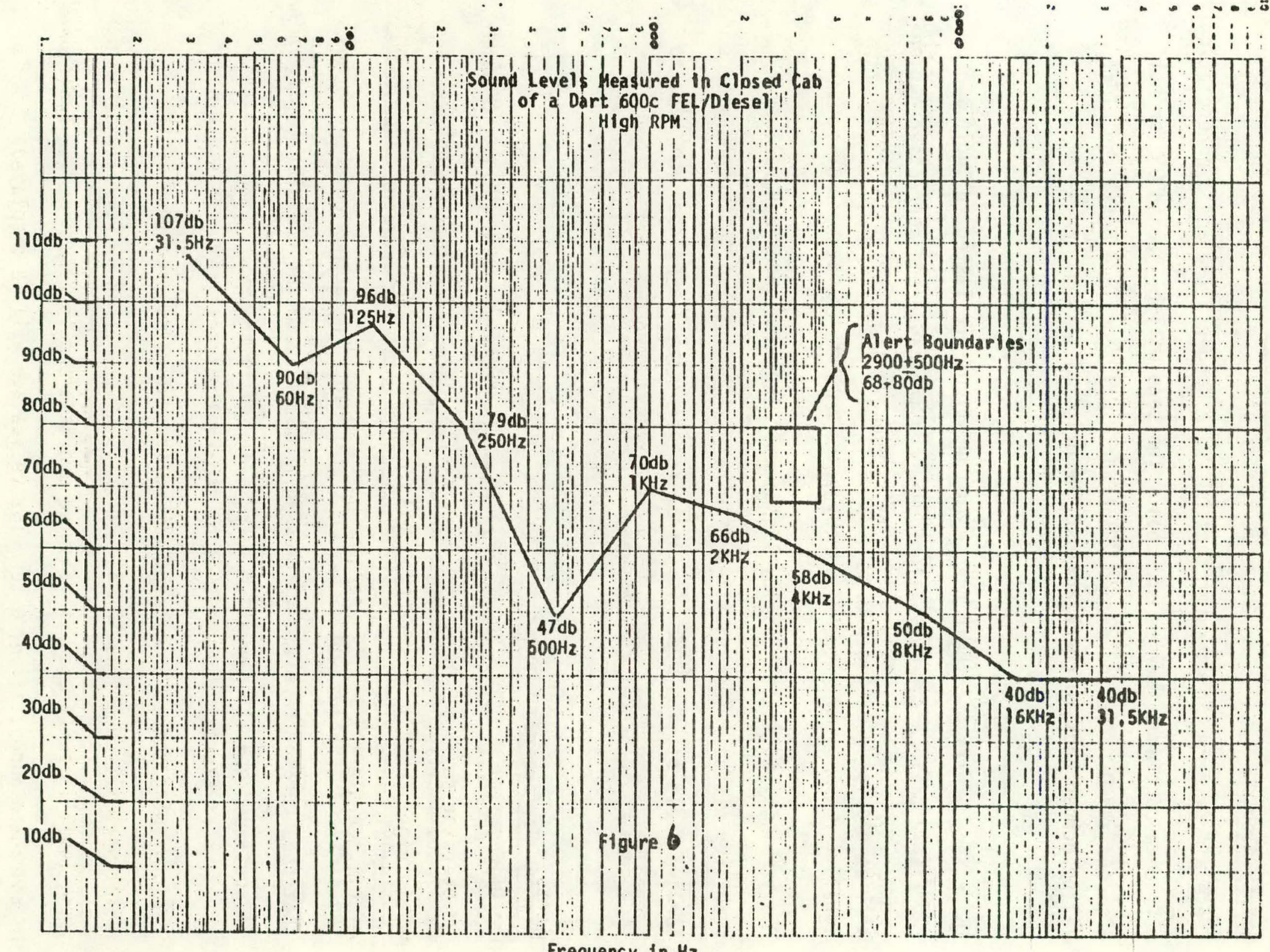




\section{Safety Alerts}

These alerts warn the operator that he is in danger. The audio annunciation will be a continuous series of beeps. The tone will be turned on for half a second and OFF for one second. The audio will continue until the alert condition is rectified.

The safety alerts and their threshold conditions are listed in Table 3. The alerts will be automatically issued and the cause and corrective action will be displayed on the LCD.

The stability indicator display lights will indicate speed and roll over stability alerts. The stability display will be located in the operator's forward field of view where it can be readily seen, so he does not have to look down to interpret the message.

\section{Machine Performance Alerts}

These alerts warn the operator that something is wrong with the FEL and that he should notify the maintenance crew. The audio annunciation will be a continuous tone. The tone will be presented until the operator acknowledges the alert by pressing the OK key on the keypad. The acknowledgement insures that the operator received the message. It is up to the operator to determine if continued operation would result in damage to the FEL. 
TABLE 3

SAFETY ALERTS

MESSAGE

AIR LOSS - STOP!

USE EMER BRAKE

BRAKE MALFN-FRNT

CAUTION

BRAKE MALFN-REAR

CAUTION

STEERING PRESS

LOW - STOP!

PARKING BRAKE

NOT ENGAGED

SPEED STABILITY

CAUTION

ROLL STABILITY

CAUTION

\section{CONDITION}

$<85$ PSI

$>200$ PSI DIFFERENTIAL

$>200$ PSI DIFFERENTIAL

$<50$ PSI AT COOLER INPUT

AFTER SHUTDOWN

REF 2.2.6

REF 2.2.6 
The machine performance alerts are listed in Table 4 . The alerts will be automatically issued and the cause and number of occurrences will be displayed on the LCD. The message will be displayed until the condition is corrected or until another alert is detected. The audible tone will be issued for every new occurrence of an alert condition. The display will al ternate performance alert messages every 15 seconds when there are multiple warnings.

\section{Oyerator Performance Alerts -}

These alerts warn the operator that something is wrong with his operating procedure. The audio annunciation will be a repeating pattern that is ON for 500 milliseconds (ms), OFF for $250 \mathrm{~ms}$, ON for $1250 \mathrm{~ms}$, and OFF for $250 \mathrm{~ms}$. This pattern will be repeated four times for a total duration of nine seconds.

The operator performance alerts are listed in Table 5. The alerts will be automatically issued and the cause will be displayed on the LCD for 30 seconds. To reduce operator annoyance, repeating the same alert will be inhibited for one minute. 
TABLE 4

MACHINE PERFORMANCE ALERT MESSAGES

ENG AIR FILTER

RESTRICTED

ENG. OIL PRESS

LOW

ENG COOLANT

TEMPERATURE

TORQUE CONVERTER

TEMPERATURE

FUEL FILTER

RESTRICTED

A I R PRESS URE

LEAK

$x \times$

AIR COMPRESSOR

ADJUST GOVENOR XX

REPLACE H.YD OIL

FILTERS

$x \times$

LOW HYO O I L

LEVEL

H I G H HY D O I L

TEMPERATURE

HYD OIL COOLER

$A$ I $F L O W$

$\times \times$

$x \times$

$x \times$

$x \times$

$x \times$
HYD OIL CONTAM

SENSOR\# 1

$x x$

HYD OIL CONTAM SENSOR\# 2

HYD OIL CONTAM SENSOR\# \#

HYD OIL CONTAM SENSOR \#4

HYD O I L. CONTAM SENSOR \#5

B ALANCED BOOM

LOW OIL LEVEL

B ALANCED BOOM.

NITROGEN PRESS $X X$

B ATTERY CHARGER

I NOP.ERATIVE

$x \times$

$x \times$

$x \times$

$x \times$

HY D P U M P \#3

HI GH TEMP

HYD OIL COOLER 
TABLE 5

OPERATOR PERFORMANCE ALERTS

MESSAGE

BUCKET SHOCK

WHEEL SPIN
CONDITION

DROPPING OR RAMMING

SPINNING 
The BITE LCD can be used in a meter mode to display running values of selected parameters. The parameters that can be selected are listed in Table 6 . The operator selects the display parameters via the keyboard.

The BITE keyboard will have 16 keys with the following legends:

\begin{tabular}{|c|c|c|c|}
\hline & A B C & D E F & \\
\hline 1 & 2 & 3 & OK \\
\hline $\begin{array}{c}\text { G H I } \\
4\end{array}$ & $\begin{array}{c}J \text { K L } \\
5\end{array}$ & $\begin{array}{c}\text { M N } 0 \\
6\end{array}$ & DIAG \\
\hline $\begin{array}{c}\text { P R S } \\
7\end{array}$ & $\begin{array}{c}\text { T U V } \\
8\end{array}$ & $\begin{array}{c}\text { W } \\
9\end{array}$ & DSPY \\
\hline CLEAR & 0 & & ENTER \\
\hline
\end{tabular}

After the system completes the power up self test diagnostic, the display will automatically display air pressure and time of day. They will remain until changed or overriden by an alert. The operator must use the keyboard to change the displayed parameters. New parameters are selected by pressing the DSPY key followed by the entry code and the ENTER key. The numeric entry code will be echoed on the LCD as the code is entered. The clear key will remove the last digit entered. Each time it is pressed, another digit will be removed. A wrong entry will result in an indication of NO SUCH THING. 
TABLE 6

METER MODE DISPLAYS

\section{PARAMETER}

Time of Day

Engine $0 i 1$ Pressure

Engine Coolant Temperature

Air Filter Pressure

Tachometer

Fuel Filter Pressure

Hydraulic 0 il Pressure

Hydraulic $0 i l$ Temperature

Hydraulic Pump Temperature

Hydraulic Pump Temperature

Hydraulic Pump Temperature

Lift Pressure

Ti1t. Pressure

Steering Pressure

Torque 0 il Temperature

Lube

Air Pressure

Hourmeter

Programmable Parameter

Programmable Parameter
DISPLAY

T I ME

ENG O I L P RES

ENG COOLLTMP

A I R F I L T E R

TACHOMETER

$F \cup[L \quad F I L T E R$

H.Y D O I L PRES

H Y D 0 I L T M P

$P \cup M P \# I T M P$.

$P \cup M P \# 2 T M P$

$P \cup M P \# 3 T$ T P

L I F T P RES

T I T PRES

STEER PRES S

TORQUE OIL

$L U B E$

AIR PRESSURE

HOURMETER

P P 1

$P P 2$
SIGNIFICANT

DIGITS

$X X: X X$

INPUT

TOD

963

$x \times X$

EOP

367

$X X X$

ECT

328

$X X X$

AF

23

$X X X X X$

$x \times X$

$X X X$ HOP

467

$\begin{array}{lll}X X X & \text { HOT } & 468\end{array}$

$\begin{array}{lll}X X X & \end{array}$

$\begin{array}{ll}X X X & \text { P2T }\end{array}$

728

$x x x$

P3T

738

$x x x x$

LP

57

$x x x x$

TP

87

$x x x x$

SP

77

$X X X$

TOT

868

$x x x$

LLP.

557

$x x x$

AP

27

$x x x x x$

$x x x x x x$

H

4

PP2

771

$X X X X X X$

PP2

772 
Each time a new parameter is entered for display, it will be shown on the top line of the display. The previous top line display is pushed down into the second line and the previous second line information is removed. To display engine coolant temperature, press the keys in the following order:

$\begin{array}{ll}\text { KEY } & \text { TOP DISPLAY LINE } \\ \text { DSPY } & 3 \\ \text { E } & 32 \\ \mathrm{C} & 328 \\ \mathrm{~T} & \text { ENG COOL TEMP. XXX } \\ \text { ENTER } & \end{array}$

The air pressure initially displayed will disppear and the LCD will show:

\begin{tabular}{|c|c|c|c|}
\hline ENG & COOL & TEMP & $x x x$ \\
\hline TIME & & & $X X: X X$ \\
\hline
\end{tabular}

Maintenance Displays

The FEL operator or maintenance man can display, on the LCD, the machine performance data that will be printed on the maintenance report. This allows the FEL stalus to be checked without requiring a report to be printed. 
The maintenance displays are activated by pressing the diagnostic (DIAG) key. The computer will search the maintenance alert list and display any alert which has occurred. The basic format is an abbreviated form of the maintenance report. The same descriptive title will be shown along with the number of occurrences. The date and occurrence time information will not be shown. A sample maintenance display is shown below:

$$
\begin{array}{lrr}
\text { REPLACE } & \text { HYD } & \text { OIL } \\
\text { FILTERS } & X X
\end{array}
$$

Pressing the DIAG key again will find the next alert with any occurrences. When there are no more alerts to display, the LCD will show:

DIAGNOSTIC DONE

NO MORE ALERTS 


\subsection{MAINTENANCE REPORTS}

The maintenance reports are obtained by. dumping the microcomputer maintenance data onto a cassette computer tape unit. After the data is dumped, the maintenance data memory area is cleared and data collection starts over. The tape unit is then taken to the maintenance shop where the report is printed.

The BITE computer and tape recorder both need power to transfer the data. The FEL can be in several conditions when this transfer takes place. There are three possibilities.

0

The machine is turned on with no tape drive plugged in.

0 The machine is turned on and the tape drive is plugged in at some time later.

- The machine is turned off and the tape drive is plugged in.

The maintenance data will consist of five duration histograms and a listing of the warnings with the number of occurrences of each warning. Examples of the histograms are shown in Figures 7,8 and 9 .

The tape recorder is used to remove the maintenance data from the machine. The data can be removed with or without the engine running. The FEL electrical system does not have to be turned on to retrieve data. During the data dump the message "DATA DUMP" will be displayed.

The printer and tape recorder will be hooked together to generate hard copy maintenance reports. The tape unit will act as the printer driver. 


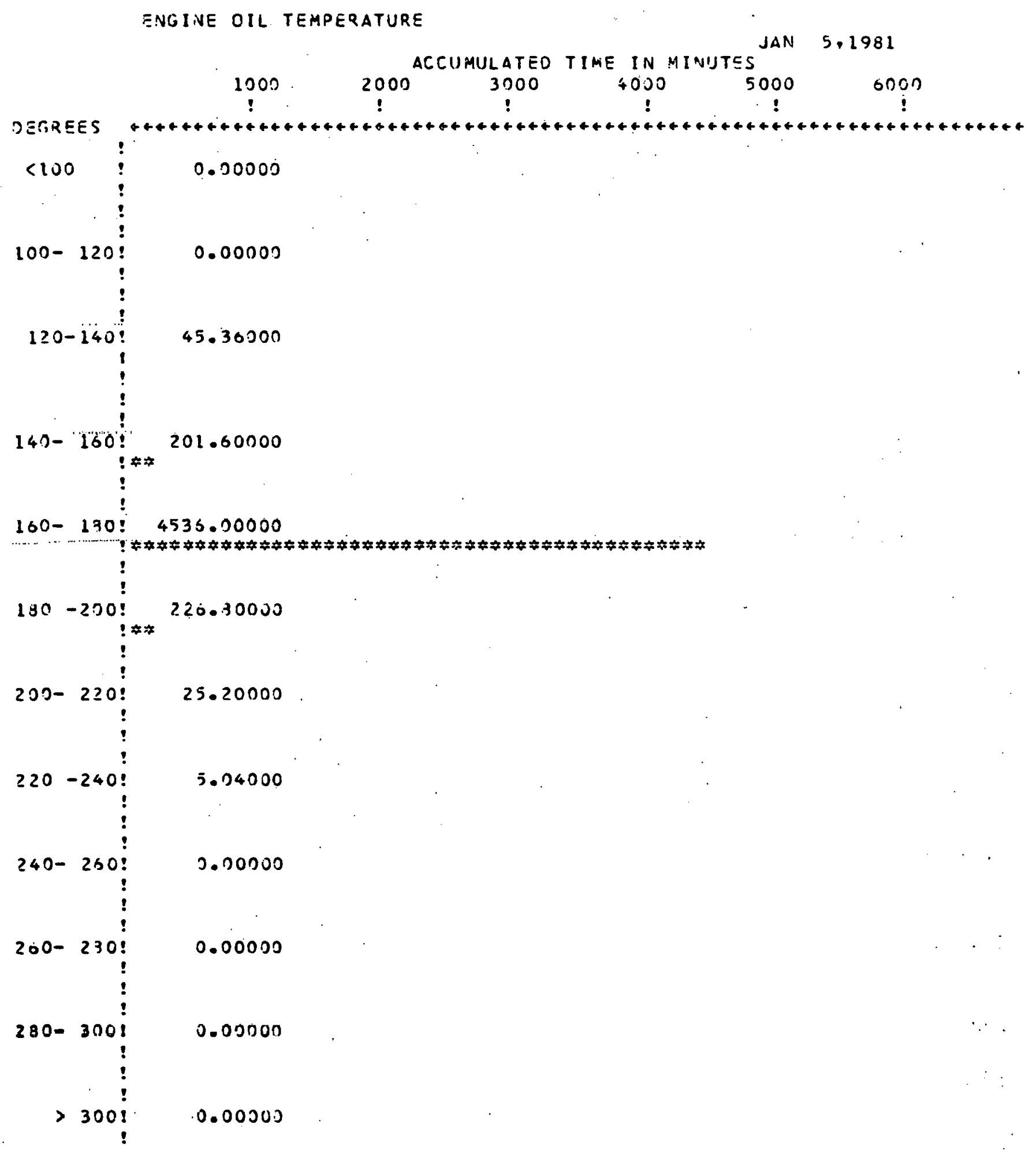




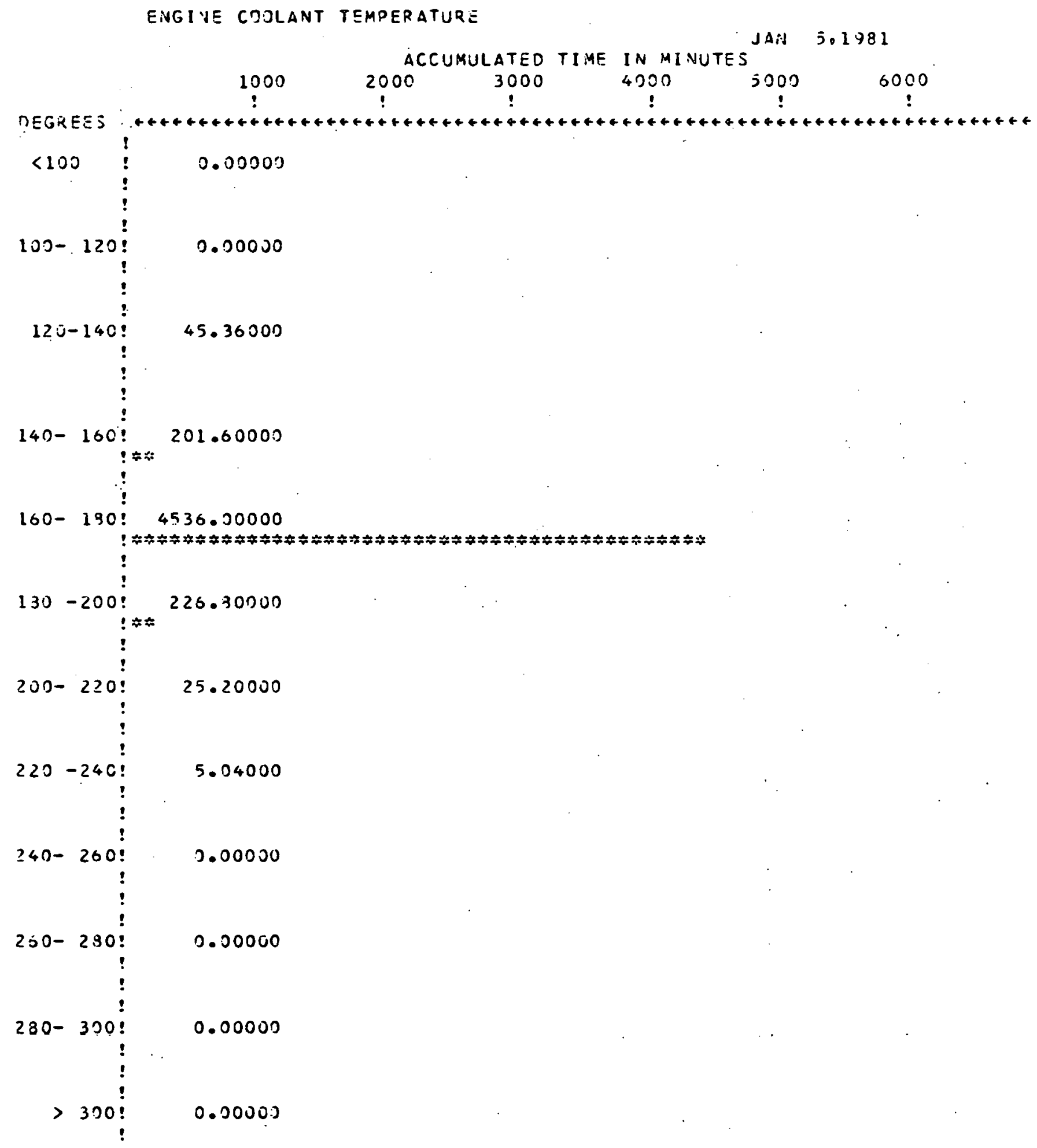




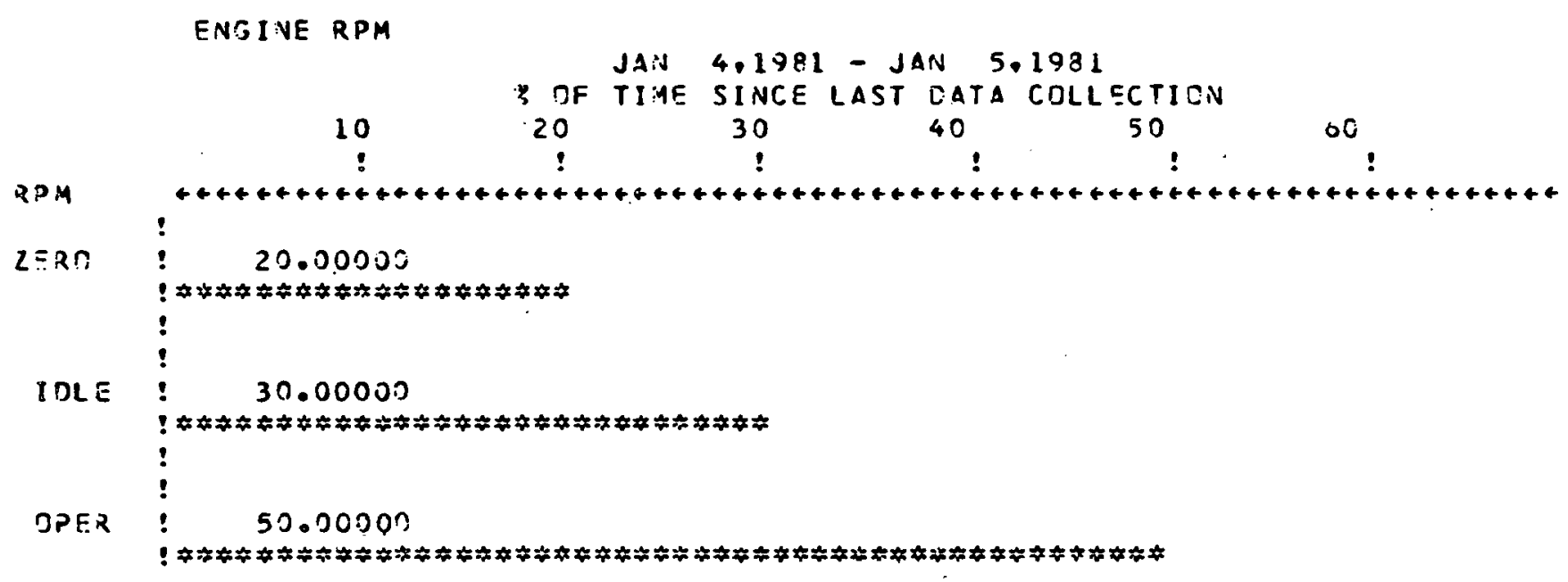


FIGURE 10

MAINTENANCE REPORT

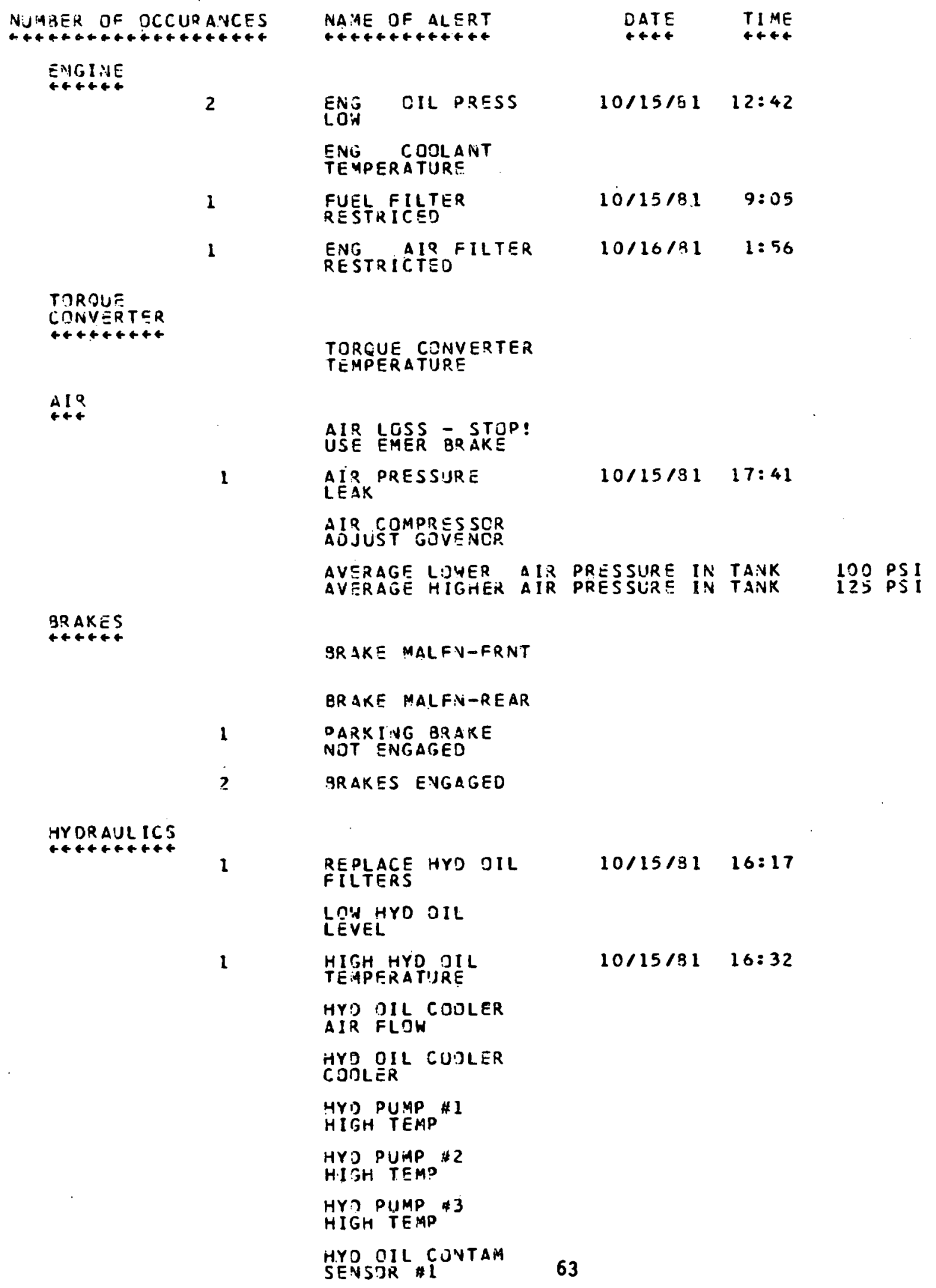




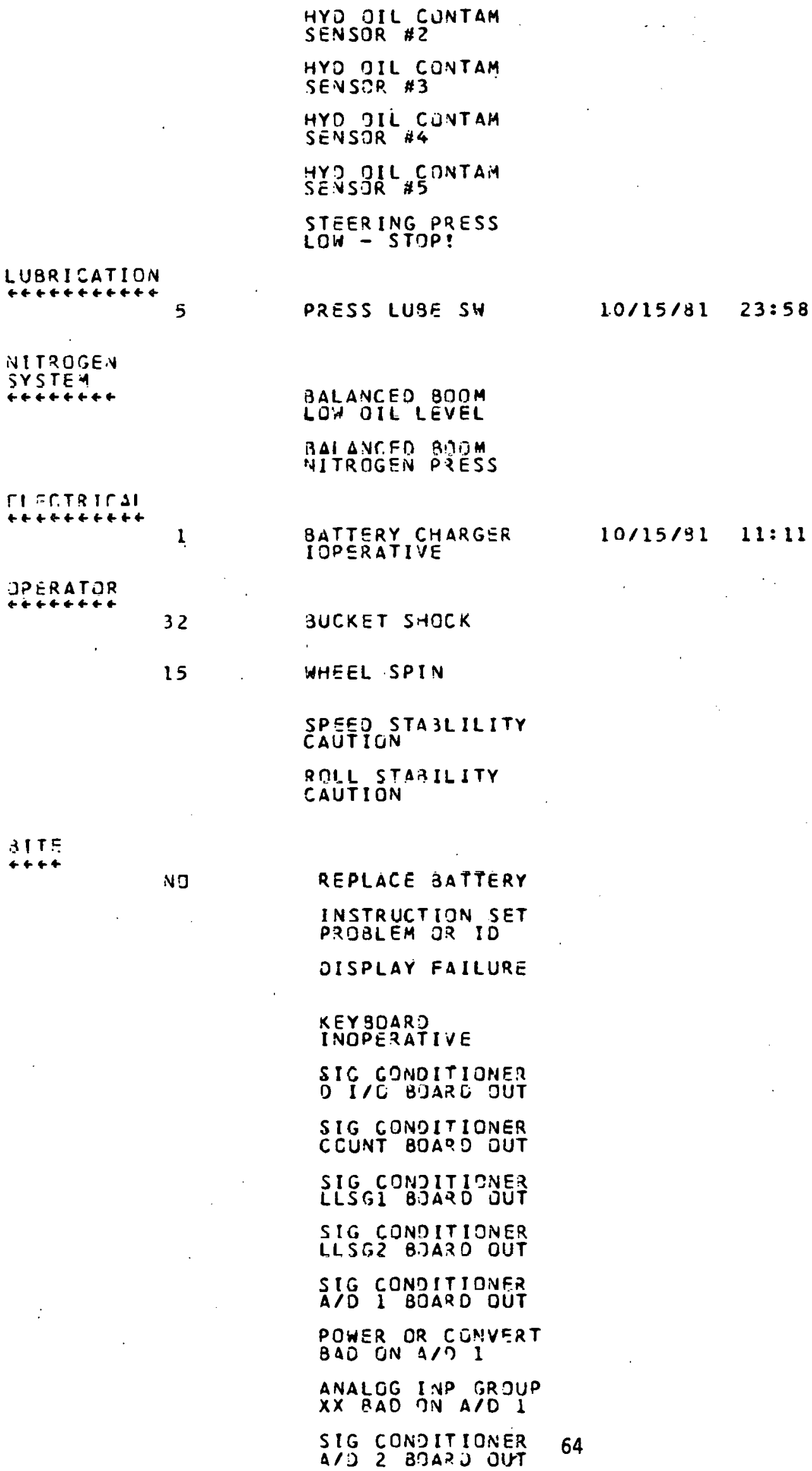


POWER OR CONVERT

ANALOG INS GROUP.

65 


\subsection{Personality Module}

The FEL machine specific and BITE system adjustment constants will be grouped and stored in a personality module. This module is nothing more than an assigned section of microcomputer memory. These constants will be stored in non-volatile electrically eraseable programmable read only memory (EEPROM) where they are immune to power losses but it is still possible to adjust the constants without recompiling and reprogramming a PROM for every different FEL. EEPROM is preferred to battery backup random access memory (RAM) because the data is locked into memory and does not need to be restored when the RAM backup batteries are replaced.

The personality constants identified to date are shown in Table 7. The initial constant values will be compiled into the BITE program. Changing the constants on the FEL can be performed by mine engineering personnel. This is not intended to be a FEL operator function. The steps to change a personality constant includes:

- Enter a 3-digit secret meter mode display code.

- Enter the identification number of the constant to be changed. The current constant value will be displayed.

o Enter the new constant value if you want to change it.

- Press the ENTER key. The display will automatically request another constant identification number.

- Repeat steps 2 through 4 to change another constant, or press ENTER a second time to return the display to normal. 
TABLE 7

\section{PERSONALITY CONSTANTS}

1. Upper limit engine oil pressure

2. Lower limit engine oil pressure

3. Upper limit engine coolant temperature

4. Upper limit air filter pressure difference

5. Upper limit fuel filter pressure difference

6. Upper limit voltage

7. Lower limit voltage

8. Upper limit hydraulic oil pressure

9. Lower limit hydraulic oil pressure

10. Upper limit hydraulic oil temperature

11. Lower limit hydraulic oil level - while operating

12. Upper limit hydraulic pump case temperature

13. Upper limit hydraulic oil filter pressure difference

14. Upper limit hydraulic oil cooler pressure difference

15. Upper limit hydraulic cylinder pressure 1 for each cylinder circuit sensed

16. Lower limit hydraulic cylinder pressure 1 for each cylinder circuit sensed

17. Upper limit torque converter oil temperature

18. Front differential reduction ratio

19. Rear differential reduction ratio

20. Front final drive induction ratio

21. Rear final drive reduction ratio

22. Wheel diameter

23. Lower limit brake fluid pressure

24. Lower limit steering oil pressure

25. Upper limit steering oil temperature 
TABLE 7

PERSONALITY CONSTANTS (Continued)

26. Upper limit air pressure

27. Lower limit air pressure

28. Upper limit of allowable wheel slip

29. Stability limit. (4)

30. Constants used to determine weight or bucket fill

31. Lower RPM for operating time to be accumulated

32. BITE Clock Hours

33. BITE Clock Min

68 


\subsection{DEVELOPMENT TOOLS}

Several software development tools will be incorporated into the BITE system to facilitate system development and evaluation. These are engineering tools and are not intended for use by mining personnel. These tools include a keypad monitor, programable histogram capability, and programmable meter mode capability.

\subsection{Keypad Monitor}

A data area will be set aside to monitor which meter mode displays the FEL operator and maintenance personnel use. This information will be used to determine the usefulness of the meter mode displays and to revise the meter mode displays at the end of the evaluation period.

\subsection{Programmable Histograms}

The maintenance report will include two keypad programmable histograms. These histograms are included to support BITE development. The steps to program the histograms include:

- Enter a 3-digit secret meter mode display code.

- Enter the identification number of the histogram to be changed.

- Enter the address of the parameter to be monitored.

- Enter the upper and lower histogram boundaries.

o Press the ENTER key. 
The upper and lower histogram boundaries program the scaling of the vertical histogram axis. The axis will be divided into ten equal segments with a below range and an above range indication on each end, see figure 6 . This flexibility permits expanding the histogram to cover the specific parameter range of interest.

The horizontal axis is fixed and will indicate duration time in minutes, up to a maximum of 6000 minutes or 100 hours.

\subsection{Programmable_Meter Mode}

The LCD will have two programmable meter mode displays PPI and PP2. These displays are included to support the BITE development. The steps to program the displays include:

- Enter a 3-digit secret meter mode display code.

- Enter the name of the display to be changed.

- Enter the address of the parameter to be monitored.

- Press the ENTER key.

The LCD will show either PPI or PP2 and the numeric value of the selected parameter. 


\subsection{REFERENCES}

Reference is made to the following documents in this report. The numerical designation of the references is shown below.

1. Built In Test Equipment (BITE) To Improve Front End Loader Productivity. DE-RP01-80ET-14052. Department of Energy, Office of Procurement Operations. July 1980.

2. Built-In Test Equipment for Front-End Loaders. Final technical report by Skelly and Loy. U.S. DOE contract NO. DE-ACO1-7.9ETd 1268. January 1980.

3. Built-In Test Equipment for Front-End Loaders - Phase II. Oraft Final Report by Skelly and Loy. U.S. DOE contract NO. DE-ACO1-79EFIl1268. November 1980. 